\title{
Transposition
}

Musique et Sciences Sociales

9| 2021

Musique et sexualité

\section{Deconstruyendo la ópera para que no muera: entrevista a Ópera Queer}

Jazmín María Tiscornia et Giselle Araceli Méndez

\section{(2) OpenEdition}

Journals

Édition électronique

URL : http://journals.openedition.org/transposition/6457

DOI : 10.4000/transposition.6457

ISSN : $2110-6134$

Éditeur

CRAL - Centre de recherche sur les arts et le langage

Référence électronique

Jazmín María Tiscornia et Giselle Araceli Méndez, « Deconstruyendo la ópera para que no muera: entrevista a Ópera Queer», Transposition [En ligne], 9 | 2021, mis en ligne le 20 avril 2021, consulté le 23 avril 2021. URL : http://journals.openedition.org/transposition/6457 ; DOI : https://doi.org/ 10.4000/transposition.6457

Ce document a été généré automatiquement le 23 abril 2021.

La revue Transposition est mise à disposition selon les termes de la Licence Creative Commons Attribution - Partage dans les Mêmes Conditions 4.0 International. 


\title{
Deconstruyendo la ópera para que no muera: entrevista a Ópera Queer
}

\author{
Jazmín María Tiscornia et Giselle Araceli Méndez
}

\section{Introducción}

1 Ópera Queer (de ahora en más, $\mathrm{OQ}$ ) es una propuesta musical teatral disidente de vanguardia cultural que desafía e indaga los modos en que somos interpelados por 300 años de herencia operística. Apelando a una puesta en escena que incluye draggeo, clown, humor y militancia por los derechos de las diversidades, las gemelas Ferni y Luchi De Gyldenfeldt acompañades ${ }^{1}$ del maestro "Luigi" al piano, se montan para prestar sus voces a una amplia variedad de repertorio operístico, transformando su género según la ocasión. Tanto Ferni de Gyldenfeldt (FdG de aquí en más) como Luchi de Gyldenfeldt (LdG) estudiaron como barítonos en la Universidad Nacional de las Artes de Argentina. Desde el comienzo de OQ fueron experimentando vocalmente, transmutando con y a través del show. El espectáculo se presenta en teatros y salas independientes de la Ciudad Autónoma de Buenos Aires (Argentina), pudiendo caracterizarlo como un espectáculo del under. Desde OQ también se lleva a cabo una intensa labor pedagógica dentro del programa Música y Género perteneciente a la Universidad Nacional de las Artes, participando en talleres sobre Educación Sexual en escuelas secundarias públicas de la Ciudad de Buenos Aires y alrededores.

$2 \mathrm{Al}$ asistir a un show de $\mathrm{OQ}$, el espectador se adentra en una hora y media de una selección de las más famosas arias y dúos de la ópera clásica, acompañadas al piano. Durante la performance, LdG deviene contratenor/sopranista para interpretar a las heroínas, mientras que FdG interpreta con voz barítona roles usualmente masculinos, alternando también con roles de mezzosoprano. La puesta incluye un importante vestuario que cambia a lo largo del espectáculo, así como maquillaje drag, joyas y zapatos de taco alto. Los momentos de música usualmente se ven interrumpidos por chistes, explicaciones bizarras sobre los argumentos de las arias o traducciones 
humorísticas de las letras hechas por les artistas. En todos los shows se suman momentos de reflexión sobre la visibilización de las disidencias.

Luchi de Gyldenfeldt se licenció en Artes Musicales por la Universidad Nacional de las Artes (UNA), con orientación en canto lírico. Realizó su debut como barítono a los 22 años en el prestigioso Teatro Roma de Avellaneda (Argentina). Ha cantado los roles de Papageno, Nardo, Guglielmo, Belcore, Gasparo, Javert, Grizabella, Musetta, Sorceress y ha realizado numerosos conciertos de música de cámara y comedia musical. Se ha presentado en las salas más importantes de Buenos Aires, incluidas el CCK, la Usina del Arte, el Teatro Avenida y el Teatro Colón.

Ferni de Gyldenfeldt se egresó de la Tecnicatura en Música en el Conservatorio Superior de Música de la Ciudad de Buenos Aires "Ástor Piazzolla". En la actualidad está realizando la Licenciatura en Canto Lírico como barítono en la UNA. Codirige y canta en el coro de Murga Estilo Uruguaya "La Notalpié". Forma parte del conjunto folklórico "Allpa Munay" abocado a la obra de Atahualpa Yupanqui.

Ópera Queer en redes:

YouTube: https://youtube.com/channel/UCIYikITlTNaS8TptQ7YKS3w

Instagram: https://www.instagram.com/opera.queer/

\section{Entrevista a Ópera Queer}

JAZmín mARía tiscornia - giselle ARACel méndez: Para comenzar, nos gustaría retomar una frase que mencionaron en la entrevista realizada para el diario argentino Página 12, donde dijeron que "Ópera Queer es un espectáculo artivista". ¿Cuáles son los elementos que hacen que Ópera Queer tenga ese carácter?

Ferni de Gyldenfeldt: Considero que ese carácter se lo da la conjunción entre elementos que podríamos pensar como típicos de alguna expresión artística, con aquellos elementos que tienen que ver con el activismo, en tanto la visibilización, la lucha y la reflexión política y filosófica sobre algún tópico en particular. De esta forma, yo creo que ópera Queer no es únicamente un evento artístico. Cuando vienen a vernos, no sólo nos ven cantar ópera: para mí no es sólo eso tampoco. No es menor que cante draggeada, o que esté maquillada de una forma en particular o que tenga tal o cual vestimenta. Eso no es menor. Ópera Queer se constituye como político en lo visible, en lo disidente, en lo queer y en las nuevas formas de hacer. Son todos esos componentes, a mi entender, los que dan forma al espectáculo: esa visibilización, esa reflexión, ese gesto político... ese permitirnos ser en libertad. Todo eso es político, contundente y fundamental. De esta forma $\mathrm{OQ}$ no es solamente " $\mathrm{iAy}$, cómo canto ópera!", sino que es todo esto otro que la constituye. $Y$ es en ese sentido que nos permite imaginarnos nuevas formas de hacer arte, nuevas formas de cantar, nuevas formas de vivir, nuevas "formas de". Pero es una misma que se corre de la que nos dijeron que era la única forma de hacer ópera, un concierto, una interpretación o una performance. Para mí son todos esos elementos los que hacen que el espectáculo o la propuesta sea una propuesta artivista y no solamente artística.

Luchi de Gyldenfeldt: En nuestro idioma y en el lenguaje hay pocas palabras que son performáticas por el simple hecho de decirlas, y me parece que justamente el artivismo es una muy poco performática, en el sentido de que construye retórica cuando la digo y cuando la nombramos, pero no genera performáticamente algo real, 
un cambio, si no ponemos el cuerpo, "la cuerpa"3. Y yo creo que somos artivistas porque ponemos la cuerpa cada vez que hacemos Ópera Queer. Eso es lo que nos define como artistas militantes por las disidencias. No únicamente porque tenemos un discurso bonito sino porque ponemos la cuerpa en cualquier escenario en el cual estemos, ya sea una calle, una feria americana, un teatro o un centro cultural. Pero la actitud siempre es la misma. De alguna forma nos gusta pensarnos, como dice Susy Shock, como catapultas: $\mathrm{OQ}$ como una catapulta para esa otra humanidad que queremos ser ${ }^{4}$.

JMT-GAM: ¿Cómo se relaciona una propuesta autogestiva como Ópera Queer con la búsqueda de mayor difusión y el ingreso a un circuito que podría denominarse "circuito comercial"?

LdG: Yo pienso que para el sistema capitalista todo tiene un precio y OQ tiene un precio para el sistema capitalista. Seguramente el precio que nos pongan va a ser muy alto de acá a un tiempo, porque lo que hacemos en términos capitalistas lo merece. Eso no significa que no seamos conscientes de que estamos en este sistema socioeconómico mundial con políticas muy claras y perversas en casi todas las esferas de la vida pública, sobre todo de la vida pública. Corremos el riesgo, por supuesto, de ser en ese sentido mercancía para un mercado capitalista que se puede quizás disfrazar de este famoso pinkwashing, hacerse les progres, hacerse les orgulloses, les disidentes y usarnos. Y en el fondo esconder con esto un montón de privilegios, esconder un montón de falta de recursos y de falta de oportunidades. Por eso es algo con lo cual con la Ferni nos venimos manejando con mucho cuidado. Porque sabemos que nos maquillamos y quedamos hegemónicas, lindas, sabemos que somos medio rubias o que tenemos un estilo medio eurocentrista. Nos sabemos privilegiadas. Nos sabemos de clase media: no nos vamos a quedar sin comer. Venimos esquivando bastante al mercado y creo que lo vamos a seguir esquivando justamente para poder construir otros escenarios que nos representen muchísimo más a las disidencias en su totalidad. Sabemos que la salida es colectiva así que en ese sentido queremos construir otros escenarios diferentes a ese mercado, y por querer justamente provocar y visibilizar nunca fuimos a un lugar sin un sentido político. Nos acercamos a lugares también desde la autogestión y de la tribu que nos iba reconociendo: desde ese lugar nacimos. Ópera Queer es, sigue siendo y será una propuesta desde ese lugar, un espacio político llano, horizontal y popular. Por eso decimos: la ópera es popular. Y la disidencia le podrá estar pareciendo interesante al capitalismo, pero no necesariamente el capitalismo le está pareciendo interesante a Ópera Queer.

JMT-GAM: Ustedes en su espectáculo se posicionan desde "lo popular", sin embargo, la ópera está asociada a escenarios elitistas ¿Cómo sostienen el ideal desnormativizador a partir de un repertorio que transita ese tipo de escenarios?

FdG: Yo creo que principalmente lo sostenemos, y me permito hablar por las dos, porque nosotras amamos a la ópera. Desde la infancia funcionó para nosotras como una especie de refugio. $\mathrm{Y}$ así, de esa forma, entendimos que si a ambas nos había podido gustar era algo que era muy poderoso y que debía de ser para todes. La ópera tiene potencia en las voces, en el drama... y provoca en todas las personas algo de lo universal que la hace muy atractiva para todes. Pensemos en la cantidad de obras que enseñan sobre la vida, sobre el amor...obras que te pueden convertir en una mejor persona. 
LdG: Por otro lado, es cierto que en los escenarios elitistas debemos tener cuidado con el pinkwashing. Porque es muy fácil decir "la ópera es para todes" para poder pedir un subsidio y seguir haciendo más de lo mismo, cantando para las mismas personas. Decir "la ópera es de todes" y hacer que tal personaje no se enamore de nadie o que sea medio maricón no es lo que necesitamos. Situaciones así pasan en muchísimos teatros del mundo. Yo he visto en el Teatro Colón cosas que decís: "¡no puede ser!" Todavía vigente el estereotipo de la mariposa, del "mariposón", del "chongo"...todo eso está años atrás. Y ahí está la diferencia cuando decimos "la ópera como nos ha sido heredada", o mal heredada, porque así nos fue heredada y desde este lugar la reproducen los entes oficiales, como ser, uno de los coliseos más importante de América Latina, el Teatro Colón. Invitar a un artiste disidente a hacer un espectáculo al año no compensa nada. "Queremos que nos incluyan", se repite en todos los ámbitos. Pero: ¿adónde? Eso ya fue. No hay que incluir a las disidencias, hay que cambiar un poco el panorama de cómo estamos pensando el territorio. Nuestras cuerpas como territorio real y después los espacios, ¿no? Saquémonos de la cabeza que solamente establecer un cupo es incluir.

JMT-GAM: ¿Podríamos pensar entonces que en $\mathrm{OQ}$ hay una búsqueda de educar sobre ópera a públicos no convencionales de este tipo de repertorio?

LdG: Sí, totalmente. Yo creo que eso es algo que empezó a ser claro con el transitar de OQ y cada vez se hace más claro. Cuando estudiamos en la universidad aprendimos que la ópera en sus orígenes era algo totalmente cotidiano. Estamos hablando de Italia en los siglos XVI, XVII o XVIII. Imagínense que cuando Giuseppe Verdi compone Rigoletto supuestamente le dijo al tenor que iba a estrenar "La donna è móbile": "Te prohíbo que la tararees en la calle". ¿Por qué? Porque la gente se la apropiaba. Era como el reggaeton de la época. Se la prohibió cantar porque sino la gente ya la iba a saber para el estreno. Eso pasaba. Así era el contexto de esta ópera romántica que hoy en día reproducimos. Por todo esto yo hoy por hoy pienso que si hay una esencia de la ópera primero es queer y segundo es popular.

Y con respecto a los públicos no convencionales, desde OQ estamos trabajando con distintas instituciones en pos de la Ley de Educación Sexual Integral ${ }^{5}$, yendo a colegios secundarios y profesorados, para participar de charlas y talleres sobre Educación Sexual y respeto a las diversidades. Todo eso no sólo es una herramienta posible para seguir visibilizándonos sino que también permite sumar otros espacios operísticos... y ahí es donde se nos muere de rabia el público habitué del Colón que no puede entender que hagamos ópera pero que seamos maricas, que hablemos con $e$, que la Ferni cante de barítono y se ponga el vestido. Bueno, quizás, para ellos, nunca seremos ópera "en serio".

JMT-GAM: Recién afirmabas que la ópera en esencia es queer ¿Por qué?

LdG: En la historia de la ópera hay un montón de datos que son increíbles. Por ejemplo, el patriarcado y la iglesia establecieron que las mujeres no podían cantar en Roma, lo cual derivó en que castraran a los hombres para que mantuvieran el registro de soprano. Eso es increíble. Hubo miles de hombres que perdieron la voz, que la castración salió mal, o que no fueron tan exitosos como Farinelli y otros, pero que también han cantado muchísimo, justamente por la prohibición a las mujeres. Imagínense, un hombre que se castraba y cantaba como soprano hacía a veces un rol femenino. Y en la obra, ese rol femenino se travestía de hombre para seducir a una dama, y muchas veces se volvía a travestir de vuelta como mucama de ese hombre del 
cual se travestía... ¡Yo creo que hoy por hoy a nadie se le ocurriría una genialidad como esa! Entonces, lo queer significa bizarro, también en ese sentido de lo que no se puede definir... Es decir, intentar definir lo queer es complejo. Hay un artículo muy lindo de Moira Pérez ${ }^{6}$, la socióloga argentina, que en una oportunidad le consultaron: “¿Vos cómo definirías lo queer? Y ella sostiene que sería muy hipócrita de su parte pretender dar una explicación o una definición sobre qué es lo queer, cuando en realidad ese término está todo el tiempo mutando y transmutando. $\mathrm{Y}$ eso es justamente lo inexplicable, lo indescifrable de la existencia, quizás del "estar haciendo", como diría Marlene Wayar ${ }^{7}$. Algo muy interesante del artículo de Pérez es que ella sostiene "que lo queer no maquille los propios privilegios". Y yo creo que ahí es algo donde volvemos un montón con $\mathrm{OQ}$, ya que pienso que como artivistas, con Ferni pudimos decodificar que lo que mejor podíamos hacer era unir la ópera que amamos con la militancia por la visibilización de nuestras corporalidades, de nuestra disidencia sexual, de nuestras identidades y las de muches otres, encontrando en el humor la clave para no morirnos en el intento. $Y$ esto es sumamente importante: es estructuralmente importante en $\mathrm{OQ}$. No es el humor en clave clown para divertir, es el humor como transmutación también: nosotras encontramos en el humor, como lo hicieron tantísimes otres artistas, la veta justa donde se entrelazan la tragedia, el drama, la realidad, la risa, y sobre todo, la posibilidad de jugar con este código en el cual estamos todo el tiempo mutando y transmutando. Así podemos, al menos en el momento que dure el espectáculo, reírnos para poder también hacer de esta existencia un lugar más placentero, sin tanto prejuicio, sin tanto castigo y sin tanta normatividad.

FdG: Realmente buscamos "otro posible amoroso"... entonces creo que eso es lo que resuena, en todes, te guste o no te guste la ópera, conozcas o no conozcas a Verdi o Mozart, o Wagner o Rossini, porque definitivamente la ópera es de todes. También hay una necesidad de limpiar eso de "lo popular"... esta contradicción, esta dicotomía planteada como lo clásico, lo lírico, que decíamos de la élite y lo popular. Hace sesenta años que nos vienen metiendo desde lo más rancio del capitalismo, el bichito de que "lo popular" es de baja calidad, es berreta o se escucha de tal forma. "Lo popular" para mí entonces es una relectura sobre todo lo que significan esos conceptos.

JMT-GAM: Retomando esa idea de un "nosotres" que busca espejar la diversidad, pero al mismo tiempo reconociendo que la ópera es un género fuertemente eurocentrado, ¿cómo es posible construir una identidad que sea latinoamericana?

FdG: Para mí porque somos eso: somos nosotras. Siempre la respuesta es ser fiel. No queremos decir "somos barrocas, europeas". Podemos jugar con todo lo que sea, pero nuestra identidad es sudaca. Por eso amamos y nos encanta empezar nuestro espectáculo cantando cumbias. Cuando apareció eso hace unos años dijimos "iiPor favor!!” y cada vez lo explotamos más. En medio del espectáculo cortamos y agarramos la guitarra, y armamos un popurrí en que cantamos desde Abba hasta Gabo Ferro. Eso lo tenemos incorporado y no podemos estar en contra, más allá de que $\mathrm{OQ}$ lógicamente se visibilice como un espectáculo lírico... Cada vez aparecen más estos guiños, estos gestos a todo lo que es nuestro crisol cultural y a lo que somos nosotras, que somos un montón de cosas. También creo que ahí aparece algo sumamente importante, que con seguridad nos ancla en una verdad: Ópera Queer es un proyecto sudaca. Para todes, para nosotras mismas, para la gente de la tribu que nos escucha, que aunque muchas veces no conoce nada de ópera, les parece 
interesante, a pesar de que en las funciones no haya subtitulado y cantemos en alemán o italiano. Y lo curioso es que eso le ha pasado también a público que no habla en español, que aunque los chistes no los entienden, sí comprenden las letras de las arias y dúos.

JMT-GAM: Retomando la búsqueda de una definición de lo queer, y centrándonos específicamente en la definición de arte queer y de música queer, nos gustaría referenciar a la musicóloga mexicana Marusia Pola Mayorga ${ }^{8}$, quien no sólo define el arte queer como un grito disidente, una no-constricción... sino que propone, como muchas otras voces latinoamericanas, una retranscripción del término queer a "Cuir", con todo lo que esto conlleva, en términos de pensar una perspectiva latinoamericana

LdG: Es muy interesante esto que traen, muchas gracias. Totalmente, somos "Ópera Cuir". De acá a un año vamos a ser Ópera Cuir.... Para reafirmar nuestra identidad latinoamericana... iy también para lograr también que todes pronuncien bien el nombre! ${ }^{9}$

JMT-GAM: Ya hablamos de cómo $O Q$ creció y se transmutó y transmuta todo el tiempo... Podemos preguntarles ahora: ¿Cómo OQ las cambió a ustedes?

LdG: Si lo pensamos a nivel vocal, yo primero me permití desarrollar el registro de sopranista y Ferni comenzó a incursionar a veces como mezzosoprano, pero en general manteniendo su registro baritonal. Después del desarrollo sopranístico, asumí mi identidad vocal como contratenor. Es decir, definitivamente el registro sopranístico funcionó como una transición para poder llegar a mi auténtica identidad vocal. Yo sé que es un espectáculo, pero hasta que no me pude asumir como contratenor, no me pude asumir como marica todo el tiempo en mi vida...Todo eso sucedió dentro de $\mathrm{OQ}$.

JMT-GAM: Pareciera que hubo como una especie de transmutación en la cual ustedes, que primero se presentaban como algo escindido de $\mathrm{OQ}$, finalmente terminaron abrazadas por el espectáculo... y fue ahí cuando pudieron revelar lo que auténticamente eran (y son).

FdG: Totalmente. Nosotras fuimos siempre eso. Primero OQ se construyó en una trinchera y tuvo que pasar un tiempo para que pudiéramos ser nosotras, lo que verdaderamente siempre fuimos.

LdG: Eso sucede porque $\mathrm{OQ}$ no es solamente un espectáculo. Es también salir a decir: “¡Che, basta!". Quizás no me llamen más para cantar porque me voy a pelear con todos los directores de ópera, pero entonces voy a salir a decirles que ¡sí!, que puedo cantar así, y no sólo yo: todas pueden cantar así. Todes podemos cantar así. En algún punto siento que hay que decir: ¡Basta! Basta de que la universidad te diga: "Vos sólo podés ser barítono, tenor o bajo" o "Vos sólo podés ser mezzo, o soprano".

Somos afortunadas, porque disponemos también de las herramientas teóricas (que no es poco) para pelearnos con la academia. Porque hay que pelearse con la academia, pero si te cuesta expresarte, si no tenés las palabras, si no pudiste terminar el secundario... es sumamente difícil ${ }^{10}$. Por eso tenemos que decir: ¡Basta de que el colectivo travesti/trans siempre esté mirando desde la esquina a la universidad ${ }^{11}$, laburando en la esquina, prostituyéndose, y nunca puedan pensar en cantar ópera! Tenemos que permitirnos y exigir que nos permitan crear, siempre desde nosotras. Como sostiene Marlene Wayar: concebirnos a nosotras mismas como nuestra primera obra de arte. 
JMT-GAM: En ese sentido, ¿cómo vivencian la tensión entre los espacios de formación académica y los de militancia por las disidencias?

LdG: Básicamente podemos pensar que la institución no es un fin en sí mismo sino un medio para conseguir esas herramientas teóricas. Sí hubo, en la Universidad, algunos espacios donde pudimos experimentar y ser libres. En la cátedra de la régisseur Bea Odoriz interpreté mi primera Lady Macbeth como estudiante y pude experimentar como contratenor, siendo formalmente barítono.

Este año, además, daremos inicio a la primera cátedra de Canto Disidente en la Universidad Nacional de las Artes. Es un orgullo para mi ser le docente de este espacio, pienso que es un gran paso para esta lucha.

JMT-GAM: A lo largo de la entrevista también se percibe que muchas de las herramientas teóricas que mencionan provienen de distintas artistas y activistas del colectivo travesti/ trans de Latinoamérica, quizás tanto o más que de personalidades dedicadas exclusivamente al ámbito académico.

FdG: Sí, absolutamente. De hecho, antes de conocer a Marlene Wayar por supuesto que ya existía la teoría queer y hoy abundan muchísimos libros que forman parte de una biblioteca feminista y disidente que una se puede acercar a leer. Todo eso es sumamente interesante, pero de alguna forma muchas veces siguen manteniendo una cierta distancia. Es decir, son pensamientos que definitivamente pueden interpelarte en lo profundo, sacudirte. Pero cuando estás en presencia de una trava y tenés la posibilidad de conversar con ella por primera vez en tu vida, es sumamente movilizante. Por eso quizás no tiene que ver exclusivamente con leer un libro, o con acercarse a alguna bibliografía a veces un poco oculta de la facultad, donde podía aparecer alguna vez un texto con guiños a cuestiones de género. Muchas veces finalmente tiene que ver más con la experiencia, con el transmitir de docentes o de, como ya mencionamos, representantes del colectivo que a una la movilizan. Ese entramado no nos lo enseñó la academia, sino que fue motivado por una búsqueda propia y potenciada por otras personas. Pero no por cualquier otra persona, sino por referentes de nuestra tribu. No es siempre la teoría. Muchas veces es: "Acá tienen el espacio para ser libres: traigan lo que quieran y jueguen. Pongan el cuerpo".

JMT-GAM: A modo de cierre, ¿cuál o cuáles son las formas en que OQ reflexiona a través del arte sobre género y sexualidad?

LdG: Es de hecho muy interesante reflexionar sobre el lugar que le damos en el espectáculo a la sexualidad. La lucha por la visibilización y la militancia por las distintas orientaciones sexuales nos anteceden históricamente, también como una lucha sudaca. Pero ahora estamos en otro momento histórico y político. Y por eso no dejamos de visibilizar que además de todo, de toda la performance, desde nuestro no binarismo estamos posibilitando repensar la sexualidad, jugando. Lo hacemos reinterpretando personajes heterosexuales de las óperas.

JMT-GAM: ¿Nos podrían dar un ejemplo?

LdG: Por ejemplo, el dúo de Il trovatore de Verdi ${ }^{12}$. Es un dúo de amor, venganza y muerte entre el Conde de Luna y Leonora. El Conde de Luna está obsesionado con Leonora y ella está enamorada de Manrico, que es el trovador del pueblo. Pero como es el Conde y tiene poder lo manda a encerrar a Manrico y básicamente viola a Leonora a cambio de no matar a Manrico. Es un dúo que tiene mucho dinamismo y desde nuestra óptica, por la forma en que compone Verdi, no transmite drama en el sentido trágico. Por eso en el espectáculo jugamos a deconstruir un poco esas dos 
cosas. Primero a Leonora la interpretamos como a una travesti (o no binarie al menos). Luego, el Conde de Luna se muestra obsesionado pero no siempre con Leonora. Finalmente en un momento no se sabe quién le gusta a quién en el dúo o quien abusa de quién en un punto. Entonces lo que hacemos es variar y sacarle el esencialismo al género y a la sexualidad. Y en ese juego de deconstrucción en realidad lo primero que aparece es la música del compositor. A través de esto lo que más nos interesa es seguir deconstruyendo la ópera pero para que la ópera no muera. Y muchas veces lo buscamos a través de subrayar y hacer todavía más exagerado el estereotipo.

JMT-GAM: ¿Podríamos decir entonces que en $\mathrm{OQ}$ hay una búsqueda de deconstrucción de la sexualidad directamente relacionada con la elección del repertorio?

LdG: Sí, absolutamente. De alguna forma, cuando exageramos en jugar o en romper ciertas historias heterosexuales buscamos retomar a Paul Preciado, cuando sostiene que como sociedad entendemos la sexualidad en términos normativos y políticos. Como si de repente la heteronorma fuera el gran contrato sociosexual que lee nuestras cuerpas y que lee nuestra sexualidad desde que nacemos. Entonces todas las personas, sean heterosexuales o no, se sienten interpeladas por esto que estamos diciendo y visibilizando, porque nadie se escapa a la heteronorma: ni siquiera una persona heterosexual. Me parece que hay una interpelación que sucede y que nadie, ningune ser humane hoy en día puede escapar a preguntárselo o por lo menos a conocerlo y saberlo. En esos términos la sexualidad está muy presente.

FdG: Digamos que la potencia de $\mathrm{OQ}$, además de acercar la ópera a lugares que no son convencionales, es decir algo respecto al género y a la sexualidad. Algo distinto, contando otro cuento del que nos contaron siempre.

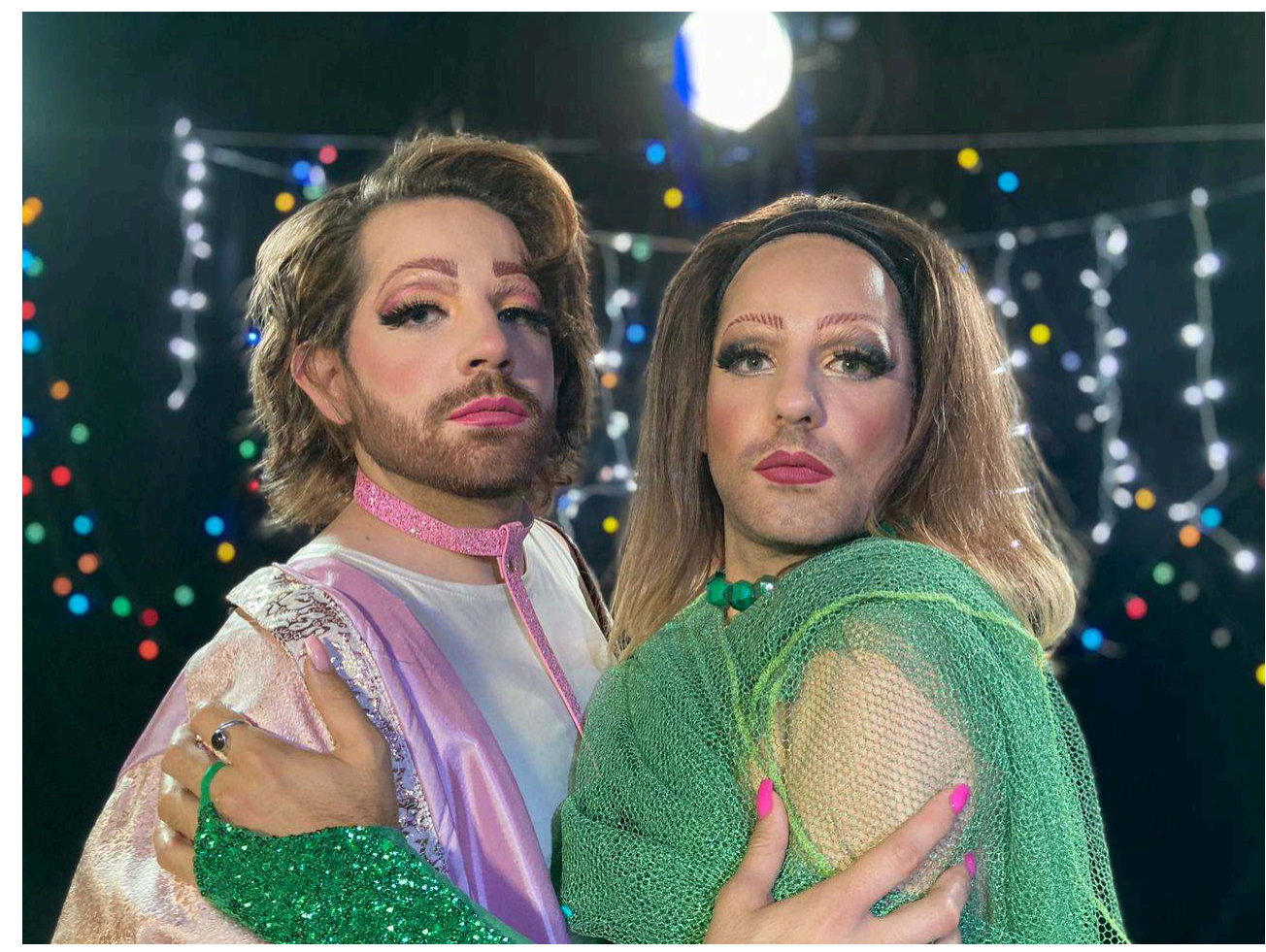




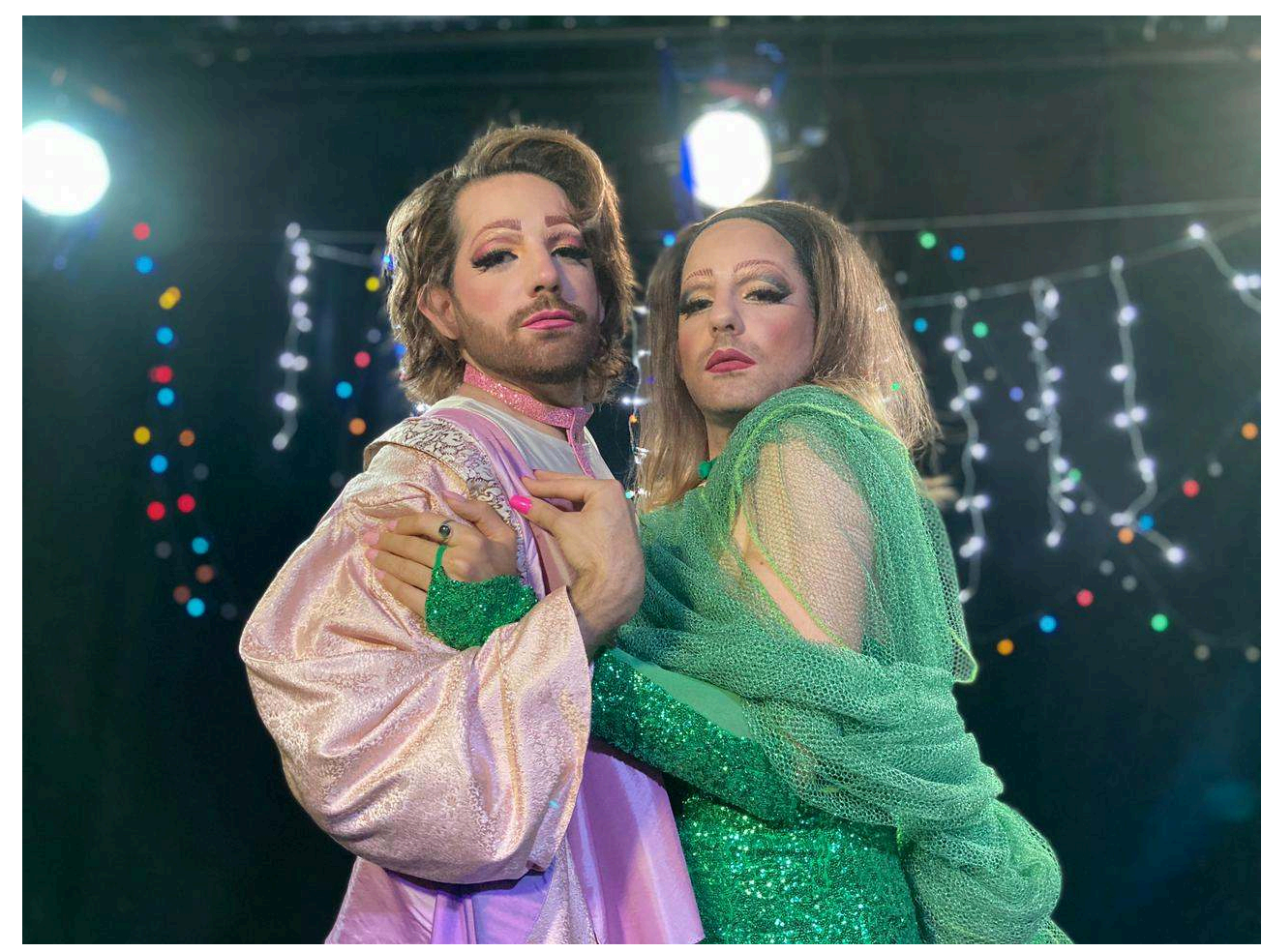

\section{NOTES}

1. Nota sobre el uso de lenguaje inclusivo: A lo largo de la entrevista se recurre al lenguaje inclusivo o no sexista, tanto por parte de les entrevistades como de las autoras, por proponer una deconstrucción de la dicotomía masculino/femenino, al reflexionar sobre el predominio del genérico masculino expresado por la vocal o en detrimento de otras alternativas. Desde hace ya años se promueve en la República Argentina, muy especialmente en el ámbito académico, el remplazo de la o por la e como expresión de género neutral.

2. GUDIÑo Leonardo, "Dar la nota", Página 12, 24-05-2019, disponible en: https:// www.pagina12.com.ar/195499-dar-la-nota (consultado el 10 de diciembre de 2020).

3. Cuerpa es una reapropiación inclusiva de la palabra cuerpo.

4. Se refieren a la icónica frase "No queremos ser más esta humanidad", del poema "Hojarascas" de la activista trans Susy Shock. En SHock Susy, Hojarascas, Buenos Aires, Editorial Pocas Nueces, 2017.

5. La Ley de Educación Sexual Integral Nro 26.150 sancionada por el Congreso de la Nación Argentina tiene como objetivo que en todos los establecimientos educativos se imparta educación sexual no sólo desde una perspectiva biologicista sino que entienda las dimensiones emocionales y sociales de la sexualidad humana.

6. PÉREZ Moira, Acerca de qué es lo queer, disponible en: https://economiafeminita.com/ acerca-de-la-pregunta-que-es-lo-queer/ (consultado el 10 de diciembre de 2020). 
7. Marlene Wayar es una activista travesti argentina, psicóloga social y fundadora de “El teje" periódico travesti/trans.

8. POLA MAYORGA Marusia, "Transfeminidades: el grito cuir y la performatividad afectiva", Escena. Revista de las Artes, Volumen 79, Enero - Junio 2020, p. 214-225.

9. En español, cuir funciona como reapropiación fonética del término queer.

10. Hace alusión a la gran cantidad de personas trans y travestis que en Argentina y en el resto del mundo ven vulnerados sus derechos de acceso a la educación, trabajo y vivienda, entre otros. Para más información, sugerimos consultar el "Informe sobre Personas Trans y de Género Diverso y sus derechos económicos, sociales, culturales y ambientales (CIDH, OEA)" disponible en: http://www.oas.org/es/cidh/informes/pdfs/PersonasTransDESCA-es.pdf (consultado el 28 de enero de 2021).

11. Esta expresión alude a la exclusión de las identidades trans de la universidad y la necesidad de incluirlas en la misma como protagonistas y no como objeto de estudio.

12. En referencia a "Udiste? Come albeggi....Mira, di acerbe lagrime... vivrá" de la ópera Il Trovatore de G. Verdi.

\section{RÉSUMÉS}

Ópera Queer es una compañía lírica disidente surgida en la Ciudad Autónoma de Buenos Aires. Entrevistamos a sus integrantes, Luchi y Ferni de Gyldenfeldt, con el objeto de explorar los modos en que el espectáculo lleva a cabo una sentida militancia en pos de la visibilización de las disidencias dentro del mundo la ópera, desde un posicionamiento latinoamericano que asimismo invita a reflexionar sobre la intersección entre música, género y sexualidad.

INDEX

Mots-clés : Ópera, queer, cuir, disidencias, género, sexualidad, Buenos Aires

\section{AUTEURS}

\section{JAZMÍN MARÍA TISCORNIA}

Jazmín María Tiscornia nació en Buenos Aires. Es pianista, egresada de la Universidad Nacional de las Artes y del Conservatorio Superior de Música de la Ciudad de Buenos Aires. También es Licenciada en Sociología por la Universidad de Buenos Aires y realiza actualmente la Maestría en Educación en la Universidad Nacional de Quilmes. Se desempeña como docente en diversas instituciones educativas. Es pianista y repertorista de la compañía Ópera Queer.

\section{GISELLE ARACELI MÉNDEZ}

Giselle Araceli Méndez es Licenciada en Antropología por la Universidad de Buenos Aires. Se desempeña profesionalmente en la Secretaría Nacional de Niñez, Adolescencia y Familia de 
Argentina. Ha colaborado con diferentes publicaciones culturales. Durante 2020 dictó junto a Jazmín Tiscornia el curso Feminismo y Música en la Universidad Nacional de las Artes. 